\title{
Novas Fontes para a História da Escravidão Negra no RS/USCPM (1850-1900)
}

\section{Vera Lúcia Maciel Barroso}

No trabalho realizado em equipe pelas historiógrafas do CEDP Centro de Documentação e Pesquisa da Santa Casa de Misericórdia de Porto Alegre,a mim coube trabalhar com os óbitos dos escravos e dos pretos livres e/ou libertos que foram sepultados no Cemitério da Instituição.

Para a compreensão dos primeiros dados colhidos, impõe-se falar sobre o próprio Cemitério, para depois analisar a sua produção documental, desde 1850 , e dela, a relativa aos negros - cativos e livres -, até 1900 , conforme foi delimitado.

Até 1850, quando começou a funcionar o Cemitério da Santa Casa, os sepultamentos em Porto Alegre eram realizados junto às Igrejas e, na própria Santa Casa (no pátio, ao fundo). Mas o Cemitério maior ficava atrás da Matriz, onde está a Cúria Metropolitana. Trata-se de uma área em declive, do que resultava uma série de problemas no Cemitério. Com a chuva, a erosão trabalhava a terra, ocasionando o descobrimento das sepulturas, provocando o mau cheiro, além das passagens inusitadas com os cães que expunham partes de cadáveres nas redondezas da Matriz. Após muito clamor da população local, providências foram tomadas para a criação de um novo cemitério fora da cidade.

Com a autorização pela Câmara da compra de um terreno extramuros (fora da cidade) em 1842, o Barão de Caxias, anos depois, fez agilizar a edificação do novo Cemitério, localizado na Colina da Azenha. Mas, somente em 1850 ocorreram os primeiros sepultamentos, a partir de 23 de maio. 
Segundo seu regulamento aprovado em 1848 , lê-se no Capítulo $1^{\circ}$, artigo $5^{\circ}$, que haverá próximo ao Cemitério um lugar destinado para sepulturas dos escravos. Este, localizado nos fundos, e separado, constitui hoje o Campo Santo, onde são sepultados os indigentes. Então, no novo Cemitério da Azenha, passaram a realizar os sepultamentos dos livres, nas quadras da frente, mas separados por irmandades, pela religião e os militares também em outro quadro, enquanto que os escravos ficavam atrás, em lugar "fora Cemitério". Igualmente os registros de óbitos eram feitos em separados: numa série, os livres, na outra, os escravos. Um volume foi encontrado relativo aos óbitos dos protestantes (período 1856-1882).

Para esta pesquisa, foram mapeados todos os dados dos 5 volumes relativos aos escravos, que de 23 de maio de 1850 , a 13 de maio de 1855 , somam 7.170 óbitos. Como no Rio Grande do Sul se tem a antecipação da liberdade, em 1884, reduzido é o número de registros até meio ano seguinte. A partir deste ano, 1885, os pretos forros passam a ser registrados na coleção dos livres.

Inicialmente, se fará algumas observações acerca DOS ESCRAVOS, com elementos contidos nos registros, resgatando todos os itens informativos, que são: número de registro, nome do escravo, cor, origem, proprietário, idade, causa mortis, ocupação, estado civil, data do sepultamento.

\section{- do nome:}

- consta somente o prenome até os anos de 1870. Poucos têm nome duplo. Ex.: Santo Antônio, Maria da Conceição. Após 70, começam a surgir com maior freqüência prenomes compostos;

- pouquíssimos aparecem sem o prenome. Por não terem sido batizados, visto terem nascido mortos, constam como "fora do eclesiástico" ou "fora do sagrado";

- equilibram-se os escravos do sexo feminino com os do masculino;

- em alguns poucos casos, o nome do escravo recém-nascido é o do proprietário;

- os nomes são comuns. Mas chama a atenção os de Esperança, Felicidade, João de Deus. Entretanto, o nome Andrezza aparece repetidas vezes. 
- da cor:

- há um número significativo de "pardos", equilibrando com os pretos;

- alguns óbitos não revelam este dado;

- aparece em número regular: mulato, cabra, morena, caboclo, indiático, trigueiro, crioulo.

- da origem:

- em alguns óbitos, não consta este dado;

- muitos referem: africano ou da África, de Nação, da Costa, d'esta província, d'esta cidade;

- poucos referem de outra província, até os anos 70. As mais referidas são Bahia, Pernambuco, Rio de Janeiro e Minas. Após 1870, acentua-se o número de pretos oriundos de outras províncias (eis o tráfico iter-regional bem evidente);

- raros são os registros de escravos de origem do Prata. Alguns vieram da Colônia do Sacramento e outros do Paraguai, especialmente durante a guerra.

- do proprietário:

- equilibram-se os e as proprietários(as);

- como escravocratas aparecem, com vários escravos, em diversos momentos:

- Dr. Manuel J. de Freitas Travassos (Provedor Santa Casa)

- Visconde de São Leopoldo

- Reverendo Thomé Luiz de Souza

- Raphael Pinto Bandeira e a sua esposa

- Conde de Porto Alegre

- Barão do Gravatay e a Baronesa do Gravatay

- Barão do Jacuy ( $\mathrm{n}^{\circ}$ significativo)

- Gen. Luiz Manoel de Lima e Silva

- Manuel Ferreira Porto - Barão do Cay ( $\mathrm{n}^{2}$ significativo)

- José Ferreira Porto - Veador Porto, irmão do Barão do Cay

- Dr. João Luiz Vieira Cansansão de Sinimbu (Pres. Província) 
- Bispo da Província

- Pe. João Ignácio de Mello

- Cap. Vasco Pinto Bandeira

- Barão do Guayba;

- verifica-se a perda de escravos de um mesmo proprietário, em curto período de tempo, por moléstias que não, de surto epidêmico. Muitos proprietários, portanto, aparecem repetidas vezes, ao longo de 1850/1885, que não os de título nobiliárquico, militar ou eclesiástico, como os citados anteriormente:

- Lopo Gonçalves Pinto ( $\mathrm{n}^{2}$ significativo)

- Clemente José Pinto ( $\mathrm{n}^{\mathrm{Q}}$ significativo)

- Eudoro Berlink

- Balthazar de Oliveira Garcia

- Paulo Augusto Cartier

- Luiz Antonio da Fontoura Palmerio

- João Baptista Soares da Silva e Souza

- Felipe Deifilippe ( $\mathrm{n}^{\circ}$ significativo)

- João Damasceno Ferreira;

- o rol de proprietários de poucos escravos é significativo;

- chama atenção os proprietários alemão e franceses em número não muito reduzido. Eis alguns:

- João Harth

- Carlos Steihart

- Carlos Humer

- Valentim Diehl

- Dr. Ricardo Helzelmann

- Henrique Leiedecker

- João Martinho Hallappe

- Lucio Frederico Whitner

- Felipe Bohrer

- Jacob Engilsdorf

- Izabel Hoeppner

- João Lindestron

- Lourenço Ceshennes

- Antonio Soury

- Pedro Fontaine

- Omir Lafoucarde 
- Nicolau Rainel

- Paulo Augusto Cartier

- Angélica Perpétua Ricaldes;

- em número não muito significativo, estão registrados escravos de propriedade da Santa Casa

- muitos escravos estão em nome de pessoa jurídica, onde consta a razão social; como:

- Dinner \& Tal

- Porto \& Irmão (trata-se do Barão do Cay e seu irmão, que tinham companhia de navegação pelo rio Cahy)

- Rocha \& Irmão

- Penedo \& Irmão

- Carvalho \& Chaves;

- alguns aparecem como escravos de herança.

- da idade:

- nos primeiros anos da década de 1850, aparece um grande número de crianças falecidas (especialmente com menos de 1 ano, o que dá uma idéia da alta taxa de mortalidade infantil. De recém-nascidos, o registro de óbitos é relevante;

- chama a atenção também a presença de muitos escravos idosos com idade superior a 80 anos, chegando a passar dos 100 anos. Ex.: Antônia, com 100 anos (falecida em 22.01.1852): de velhice; Philippe, com 110 anos (falecido em 22.06.1852): de colite; João, com 120 anos (falecido em 12.02.1855): de velhice.

- da ocupação:

- raramente é referida. As registradas são: copeiro, cozinheir(a), pintor, padeiro, tamanqueiro, bolieiro, alfaiate (ou auxiliar), jornaleiro, oleiro, remador, campeiro, cangueiro, carpinteiro ( $\mathrm{n}^{2}$ significativo), calafate, roceiro, pedreiro ( $\mathrm{n}^{2}$ significativo), sapateiro;

- consta um número regular de preso civil, preso de correição (sem sentença), preso sentenciado.

- da "causa mortis":

- é bem evidente o alto índice de mortalidade infantil motivada especialmente por mal de 7 dias (gangrena no umbigo) e dentição (com meses); 
- é também significativo o número de crianças que morrem por falta de assistência médica;

- o índice de mortalidade causada por doenças respiratórias, especialmente pulmonares, é alto, registrado sob diversas denominações, como: bronco-pneumonia, pneumonia e pneumonia aguda, tísica pulmonar e tuberculose pulmonar ( $\mathrm{n}^{2}$ significativo), pulmonia, congestão pulmonar, abcesso pulmonar, peripneumonia, tosse convulsa, pleuropneumonia, coqueluche, catarro pulmonar, tosse ou tosse convulsa, febre satarral, bronquite, afecção pulmonar, pneumonitez;

- relevante é o registro de óbitos por doenças do aparelho digestivo, como: gastro-entero-colite, gastro-enterites ou enterites/colite, diarréia ( $\mathrm{n}^{\mathrm{Q}}$ significativo), desinteria, hepatocolite;

- encontra-se um número relativo de afogamentos, especialmente de escravos marinheiros, registrado em alguns como "asfixia por submersão". Exemplo que chamou atenção: a mãe asfixiou os dois filhos menores e depois a si;

- número relativo de suicídio por enforcamento: "suicídio voluntário";

- é alto o número de óbitos de escravos com mais de 60 anos motivados por lesão orgânica do coração;

- há uma relação evidente entre preso civil e causa mortis por bexigas confluentes (contágio);

- número regular de escravos encontrados mortos no "beco tal", à beira do rio", "nos fundos da chácara de fulano de tal";

- poucos têm a referência do falecimento ter ocorrido na Santa Casa;

- fica bem evidente o período dos surtos epidêmicos: de dezembro de 1855 a março de 1856, ocorreu o de "Cólera morbus" com altíssima mortalidade; ano 1867, novamente a mesma epidemia, também registrada como gastro-entero-colites ou gastroenterites, $\mathrm{e}$ muitas vezes como moléstia reinante;

- o rol de causa mortis é muito numeroso. Percebe-se porém que se pode agrupar doenças que tiveram, ao longo do tempo, denominação alterada; e, outras não foram encontradas. Sua denominação é totalmente desconhecida, requerendo uma posterior interpretação. Ex.: boubas, combustão, suspensão. Muito auxiliou a pesquisa o 
- é também significativo o número de crianças que morrem por falta de assistência médica;

- o índice de mortalidade causada por doenças respiratórias, especialmente pulmonares, é alto, registrado sob diversas denominações, como: bronco-pneumonia, pneumonia e pneumonia aguda, tísica pulmonar e tuberculose pulmonar ( $\mathrm{n}^{\circ}$ significativo), pulmonia, congestão pulmonar, abcesso pulmonar, peripneumonia, tosse convulsa, pleuropneumonia, coqueluche, catarro pulmonar, tosse ou tosse convulsa, febre ratarral, bronquite, afecção pulmonar, pneumonitez;

- relevante é o registro de óbitos por doenças do aparelho digestivo, como: gastro-entero-colite, gastro-enterites ou enterites/colite, diarréia ( $\mathrm{n}^{\mathrm{Q}}$ significativo), desinteria, hepatocolite;

- encontra-se um número relativo de afogamentos, especialmente de escravos marinheiros, registrado em alguns como "asfixia por submersão". Exemplo que chamou atenção: a mãe asfixiou os dois filhos menores e depois a si;

- número relativo de suicídio por enforcamento: "suicídio voluntário";

- é alto o número de óbitos de escravos com mais de 60 anos motivados por lesão orgânica do coração;

- há uma relação evidente entre preso civil e causa mortis por bexigas confluentes (contágio);

- número regular de escravos encontrados mortos no "beco tal", à beira do rio", "nos fundos da chácara de fulano de tal";

- poucos têm a referência do falecimento ter ocorrido na Santa Casa;

- fica bem evidente o período dos surtos epidêmicos: de dezembro de 1855 a março de 1856, ocorreu o de "Cólera morbus" com altíssima mortalidade; ano 1867, novamente a mesma epidemia, também registrada como gastro-entero-colites ou gastroenterites, e muitas vezes como moléstia reinante;

- o rol de causa mortis é muito numeroso. Percebe-se porém que se pode agrupar doenças que tiveram, ao longo do tempo, denominação alterada; e, outras não foram encontradas. Sua denominação é totalmente desconhecida, requerendo uma posterior interpretação. Ex.: boubas, combustão, suspensão. Muito auxiliou a pesquisa o 
- numero regular de pretos ou pardos forros, sem identificação, encontrados mortos na rua ou na praia, na condição de abandonados, e mandados sepultar por ordem do Delegado.

- da idade:

- grande número com mais de 50 anos, mas não tantos com mais de 80 anos;

- um excessivo número de recém-nascidos. A partir de 1870 (com a Lei Ventre Livre), acentua-se de forma aviltante o número de crianças falecidas. Tais registros dão a idéia do abandono das crianças logo após ao nascer.

- da cor:

- onúmero de pretos equilibram-se com os de pardos. Destes, apenas se tem feito o rol do número de registros;

- como nos códices dos escravos, aparecem os de cor trigueira, morena cabra, mulato, indiático, além de muitos brancos.

- da origem:

- Estão registrados como: africano livre ou da África, de Nação, da Costa, ou Congo, Benguella, Nagô, Monjolo, d'esta Província, d'esta Cidade, da República Oriental (poucos), do Paraguai, de outras provincias, como a Bahia, Pernambuco, Rio de Janeiro.

- da filiação:

- quando menor, aparece o registro de filiação, como filho(a) do escravo(a) ..............................................., complementado com 0 nome do proprietário. Com estes registros, dentro dos livros "dos livres", se pode levantar os escravocratas ao longo do periodo trabalhado.

- do proprietário:

- aparece nos registros dos menores e é significativo a partir de 1870;

- os proprietários são, na sua maioria, aqueles mesmos registrados nos livros de escravos, especialmente os maiores ficam bem evidenciados;

- para um estudo de caso é interessante o registro de propriedade de escravo de Apolinário Porto Alegre. Este porém fazia parte do grupo de intelectuais do "Partenon Literário", uma agremiação 
literária dos fins dos anos 1860 e anos 1870. Esta é considerada a precursora da causa da abolição no Rio Grande do Sul. E dela faz parte uma escravocrata;

- outro registro interessante é o de número 9.524 (vol.16) que declara acerca de Malvina, parda de 3 anos, filha natural da preta Joaquina Maria da Conceição, manutenida judicialmente na sua liberdade e depositada em casa de seu curador João Capistrano de Miranda e Castro. (Eis a Lei do Ventre Livre.)

- da "causa mortis":

- verifica-se um número maior de "pretos livres" do que de "pretos escravos" (cf. livros respectivos) que tem como causa mortis enforcamento, afogamento ou asfixia por submersão (nestes, geralmente marinheiros). Estes eram encontrados na Praia do Navegantes ou no Cais do Porto;

- nos períodos de inverno, há registros de asfixia por congelação ou congelação simplesmente;

- há também muitos casos de abandono, ignorando-se os dados dos falecidos, que foram sepultados por ordem do delegado;

- causas mais comuns registradas: de repente (tem muita relação com apoplexia fulminante), velhice, marasmo, decreptude, lesão orgânica do coração, hipertrofia do coração, sem assistência médica (grande número), mal de sete dias, dentição, ao nascer (grande número), diarréia, doenças respiratórias, estas últimas causas da alta mortalidade infantil;

- número relativo de falecidos no "Beco Tal", na porta da Capela dos Passos (Santa Casa), em frente à Igreja do Rosário, no Caminho Novo..., ignorando-se a causa mortis;

- cerca de 1/3 dos óbitos referem que o falecimento ocorreu na Santa Casa;

- um número relativo de pretos vinham do interior da Província para serem tratados na Santa Casa, muitos deles acabaram falecendo pelo tardio atendimento prestado, do que propriamente da doença.

- do estado civil:

- pouco é referido. Destes, na sua maioria são solteiros. 


\section{- da ocupação:}

- dos seus dados colhem-se elementos para o estudo da inserção dos pretos no mercado de trabalho. Todavia, raramente é referida a ocupação. Dos poucos registrados, encontram-se: destacados da Guarda Nacional, soldado ( $\mathrm{n}^{\circ}$ significativo, especialmente durante a Guerra do Paraguai, e muitos são da Cia. dos Inválidos), barbeiro, marítimo, lavadeira, sapateiro, carpinteiro, alfaiate, calafate, lenheiro, cozinheira, doméstica, fogueteiro, músico;

- há referência de muitos mendigos.

Finalmente, algumas considerações devem ser destacadas.

É corrente na historiografia brasileira e regional a idéia de um predomínio da população negra na Bahia, em Minas e nos estados do Nordeste. E do sul, se fala de um verdadeiro "branqueamento" da população, visto o movimento imigratório do século XIX ter sido intenso para a Província do Rio Grande do Sul, com muitas levas de alemães, italianos, poloneses e outros.

Todavia, com os elementos já colhidos nesta pesquisa, esta assertativa terá que ser reavaliada. Eis os dados até 1881 já levantados:

Número de óbitos de escravos

Numero de óbitos de livres

Total de óbitos

Detalhando: dos 32.250 óbitos:

- $\quad 7.170$ são pretos escravos;

- 4.055 são pretos livres;

- 4.807 são pardos livres; 16.032

Este número revela que apenas metade da população era branca. $\mathrm{E}$ mais: da parcela-metade dos pretos e pardos não constam os mestiços, indiáticos, trigueiros, cabras, caboclos e morenos. Com estes, subiria o número da população não branca do Rio Grande do Sul, mesmo com a clareza de que, dos municípios mais longínquos da capital, não eram enviados escravos pretos forros para serem tratados na Santa Casa. 
Tem-se pois dados concretos para repensar a tese do branqueamento a população gaúcha. Aqui o convite a quem se anime a prosseguir este trabalho, cuja documentação se encontra, à disposição, no CEDOP. Endereço: Santa Casa de Misericórdia de Porto Alegre - Rua Professor Annes dias, 285, Porto Alegre, RS - Horário: 08h às 17h30min. 